\title{
The Correlation of Length of Stay in Intensive Care with Duration of Ventilator Support Usage toward Post-COVID- 19 Syndrome Incidence and Mortality in COVID-19 Survivors
}

\author{
Danu Prasetyo Irawan Winoto ${ }^{\mathrm{a}}$, Edward Kusuma ${ }^{\mathrm{b}, c^{*}}$, Soni Sunarso Sulistiawan ${ }^{\mathrm{b}, \mathrm{c}}$, \\ Bambang Pujo Semedi ${ }^{b, c}$, Hamzah $^{\text {b,c }}$, Christrijogo Sumartono ${ }^{\mathrm{b}, \mathrm{c}}$ \\ aStudy Program of Specialist in Anaesthesiology and Reanimation, Department of Anaesthesiology and \\ Reanimation, Faculty of Medicine Universitas Airlangga \\ bepartment of Anaesthesiology and Reanimation, Faculty of Medicine Universitas Airlangga \\ ${ }^{\mathrm{c} D}$. Soetomo General Academic Hospital, Surabaya, Indonesia
}

*Corresponding author: Edward Kusuma, email: edu@ anestesi-surabaya.com

\begin{abstract}
COVID-19 patients have some clinical manifestations, from the mildest form to the critical. Patients who survived COVID19 have a risk of developing persistent organ systems impairment for more than 12 weeks, namely post-COVID-19 Syndrome (PCS). This study aimed to analyze the intensive care length of stay and duration ventilator support usage as predictors of PCS incidence and mortality in COVID-19 survivors. This observational analytic study included COVID-19 patients who were taken care of in the Intensive care unit (ICU) of Dr. Soetomo General Hospital who were affirmed to be revived from COVID-19 from May to November 2020. PCS symptoms were investigated via telephone to the COVID-19 survivors and responsible family/ relatives. ROC analysis was generated to identify the comparison and the cut-off of ICU length of stay and ventilator usage toward PCS and mortality in COVID-19 survivors. A total of 104 study participants who agreed with the informed consent and were eligible for this study, were followed up. The median length of stay in ICU was 8 days, and the average duration of ventilator usage was 8,9 days. Mortality occurred in 22 participants $(21,2 \%)$. PCS after intensive care was experienced by 44 patients $(53,7 \%)$. The most frequent symptoms were: fatigue, cough, and insomnia. There was a significant result of ICU length of stay in PCS patients $(\mathrm{p}<0,001)$. The cut-off point of ICU length of stay toward PCS incidence was 8 days $(\mathrm{AUC} 0,824)$ with a Relative Risk (RR) of 2,5 (1,7-3,7). A significant difference was documented in the length of ICU stay with mortality ( $\mathrm{p}=0,042$ ). The cut-off point of the length of stay with patients' mortality was 8 days (AUC $0,641)$ with RR $2,4(1,1-5,2)$. Neither PCS incidence nor mortality was significantly correlated with ventilator usage. ICU length of stay was a predictor of PCS incidence and mortality in CODID-19 survivors after the intensive care. Duration of ventilator support usage was not correlated with the PCS incidence and mortality in COVID-19 survivors after the ICU discharge.

Keywords: Length of stay, post COVID-19 syndrome, ventilator, mortality
\end{abstract}

\section{Introduction}

According to the World Health Organization (WHO) on February 2021, the total COVID-19 case was approximately 111 million cases worldwide, with cure rate of 62,7 million cases and mortality rate of 2,46 million. In Indonesia, 1,23 million cases were confirmed by $17^{\text {th }}$ of February 2021, alongside with 1,04 million survivors and 33.596 non-survivors. A relatively higher mortality rate was documented and needed the improvements of better treatments and strategies to overcome COVID-19 cases.(1)

Virulence factor of SARS-COV-2, the virus causing COVID-19, as well as the host immune response play significant role to the severity of COVID-19 manifestation. SARS-COV-2's cytopathic effect to defeat the immune response of host, and immune system dysregulation of the host leads to the advancing of tissue damage in COVID19. Howbeit, exaggerate immune response will also cause tissue damage. When SARS-COV-2 penetrate to human cells, the antigen is presented to APC (Antigen Presenting Cells), especially depending on MHC (major histocompatibility complex) class I. The antigen presentation give rise to humoral and cellular immune response from cell $\mathrm{T}$ and $\mathrm{B}$, specifically to the virus. In humoral immune response, IgM and IgG were formed against SARSCOV-2. IgM is diminished by the end of $12^{\text {th }}$ week, and IgG persists until the long period of time. A prior research of SARS survivor showed that Cell T CD4+ and CD8+ memory cells were still could be found after 4 years, but with a decreasing manner without the presence of the antigen. SARS-COV-2 has a potency to induce multiple vesicle membrane that do not show a pattern recognition receptor (PRRs) and be able to replicate into these vesicles IJRP 2022, 92(1), 521-527; doi:.10.471 19/IJRPIO0921120222725 
so that could not be traced by the host immune cells.(2)

A study from Italy (3) demonstrated that $87,4 \%$ of COVID-19 survivor experience persistency of symptoms for at least 1 symptom, and $55 \%$ had 3 or more symptoms that lasts for over 12 weeks. PCS was more frequently characterized by persistent fatigue, shortness of breath, mental conditions, and reduction in quality of life. Another study also explained that olfactory mucosa sampling from patients showing long-term persistence of COVID19-associated anosmia revealed the presence of virus transcripts and of SARS-CoV-2-infected cells, together with protracted inflammation. Inflammation in the olfactory neuroepithelium responsible for persistent or relapsing symptoms of COVID-19, such as anosmia.(4)

The virulence of SARS-COV-2 virus and its potency to cause PCS are an interesting subject to be explored further. Therefore, we conduct a study that analyze the outcomes of COVID-19 survivor who were taken care at ICU to become an evaluation in medical service so it will be more integrated that the better long-term outcome will be achieved after ICU discharge.

\section{Methods}

2.1 Study design

This analytic observational study was conducted in ICU isolation room for COVID-19 in DR Soetomo General Hospital, Surabaya, Indonesia, from May to December 2020. Data collection and follow up were using the electronic medical record with patients record form containing patients' identity and the study variables.

\subsection{Study population}

We included adult patients aged 18 years old or older, who were confirmed by PCR to have COVID-19 and were taken care in isolation room ICU for COVID, whom related family members were agreed to be interviewed and signed the informed consent, and also the patients who were survived from COVID-19 or were discharged from the isolation room ICU. We excluded patients or family members who refuse to signed the informed consent of this study, and COVID-19 patients taken care in COVID-19 isolation room ICU who were passed away during the hospital stay. Patients with concomitant severe head injury were also excluded from this study. A consecutive sampling was used to include all eligible patients from the period from May to December 2020.

\subsection{Variables and outcomes}

Among the COVID-19 patients who were taken care in COVID-19 isolation room in our center, the survived patients after discharge were followed-up for the subsequent post-COVID-19 Syndrome (PCS) and mortality for 12 weeks. The intermediate variables in this study were the length of stay in intensive care unit and the duration of ventilator support usage.

\subsection{Measurements}

COVID-19 patients in our study were confirmed using PCR (polymerase chain Reaction) test from nasopharyngeal and oropharyngeal swabs. COVID-19 survivors were patients who were diagnosed with COVID19 that had been cured from COVID-19, whose virology swab results were negative for 2 consecutive testing. PCS was defined as the presence of COVID-19 related symptoms and signs developed during COVID-19 infection and continued for over 12 weeks after cured from COVID-19, and not because of the other presenting disease. This condition tends to pop-up with several overlapping symptoms that could change time after time, affecting many organ systems. PCS also could be presented as long fatigue with mental issues. The symptoms that could be present such as: cough, shortness of breath, chest pain, headache, myalgia, arthralgia, dysgeusia, anosmia, diarrhea, mood swings, insomnia, and tiredness.(5)

Mortality from COVID criteria according to the World health Organization.(1) Mechanical ventilator usage criteria for COVID-19 patients according to governmental guideline Indonesia from Burhan et al.(6) The length of stay was calculated from the first day COVID-19 patients was placed in isolation room ICU for COVID-19 until the day they were discharged from this room.

\subsection{Statistical analysis}

Descriptive statistics was performed using univariate analysis. Bivariate analysis comparing the independent variable and dependent variables used two independent T-Test with significance of $<0.005$. C-statistics were generated and presented using Receiver operating characteristic (ROC) curves to display the sensitivity, 
specificity and AUC (Area under Curve) of each predictor and outcome.

3. Results

3.1 Baseline characteristics

A total of 299 patients were admitted to COVID-19 isolation room ICU, of these, 104 patients were eligible and signed the informed consent for joining this study, the other 195 patients were excluded. Ten out of 195 patients had trauma, 7 patients were loss to follow-up, 8 patients underwent post-surgical care, and 170 patients were died during the hospital care. baseline characteristics of the study showed that the average COVID-19 survivor age was 52 years old, woth domination of male gender. Body mass index (BMI) was significantly contributed to morbidity, mortality, and PCS in this study. Median BMI of the study participants was $25,4 \mathrm{~kg} / \mathrm{m}^{2}$. The most frequent comorbidities in these patients were Diabetes mellitus in 45 patients $(43,3 \%)$ and hypertension in 33 patients $(31,7 \%)$. Subjects using ventilator was $35,6 \%$, with the mean usage duration of $8,9 \pm 5,5$ days. The median ICU length of stay was 8 days with $21.2 \%$ of mortality and PCS incidence of $42.3 \%$. (Table 1 )

Table 1 Baseline characteristics of the subjects

\begin{tabular}{|c|c|c|c|}
\hline Characteristics & $\begin{array}{c}\mathrm{N}(\%) \\
104(100,0 \%) \\
\end{array}$ & $\begin{array}{c}\text { Mean } \pm \text { SD/ Median } \\
\text { (Interquartile) }\end{array}$ & P-Value \\
\hline \multicolumn{4}{|l|}{ Gender } \\
\hline Male & $61(58,7 \%)$ & & \\
\hline Female & $43(41,3 \%)$ & & \\
\hline Age (years) - median (IQR) & & $52,0(16,0)$ & 0,006 \\
\hline BMI $\left(\mathrm{kg} / \mathrm{m}^{2}\right)-$ median (IQR) & & $25,4(5,5)$ & 0,000 \\
\hline Length of stay (days) - median (IQR) & & $8,0(6,0)$ & 0,000 \\
\hline Ventilator usage duration (days) - mean $\pm \mathrm{SD}$ & $37(35,6 \%)$ & $8,9 \pm 5,5$ & 0,116 \\
\hline Post COVID-19 syndrome & $44(42.3 \%)$ & & \\
\hline Mortality & $22(21,2 \%)$ & & \\
\hline \multicolumn{4}{|l|}{ Comorbidities } \\
\hline Diabetes mellitus & $45(43,3 \%)$ & & \\
\hline Hypertension & $33(31,7 \%)$ & & \\
\hline Liver function impairment & $18(17,3 \%)$ & & \\
\hline Renal impairment & $12(11,5 \%)$ & & \\
\hline Asthma, pulmonary tuberculosis & $3(2,9 \%)$ & & \\
\hline Heart failure, Coronary disease & $5(4,8 \%)$ & & \\
\hline Arrhythmias & $2(1,9 \%)$ & & \\
\hline $\begin{array}{l}\text { Other (dyslipidemia, malignancy, hypothyroid, } \\
\text { anxiety) }\end{array}$ & $6(5,8 \%)$ & & \\
\hline Highest SOFA score - median (IQR) & & $5,0(3,0)$ & 0,000 \\
\hline CRP - median (IQR) & & $10,5(13,5)$ & 0,000 \\
\hline Lactate concentration (- median (IQR) & & $1,8(1,5)$ & 0,000 \\
\hline Procalcitonin - median (IQR) & & $0,28(0,83)$ & 0,000 \\
\hline Lowest PF ratio - median (IQR) & & $100,0(63,8)$ & 0,000 \\
\hline
\end{tabular}

*normality test (Kolmogorov-Smirnov), normally distributed if $\mathrm{p}>0,05$

3.2 Patients with PCS and its correlation with the length of stay

Among the survived COVID-19 patients, 82 patients were followed-up for the development of PCS. A total of $44(53,7 \%)$ of these patients developed PCS with the most common symptoms of fatigue in $79,5 \%$ patients, prolonged cough in $40,9 \%$ patients, and insomnia in $29,5 \%$ of the patients (Table 2 ).

Table 2 . Distribution of PCS symptoms

\begin{tabular}{ll}
\hline PCS symptoms & $\mathrm{N}(\%)$ \\
\hline Insomnia & $44(100,0)$ \\
Myalgia/arthralgia & $13(29,5)$ \\
Fatigue & $7(15,9)$ \\
Cough & $35(79,5)$ \\
Shortness of breath & $18(40,9)$ \\
Tingling & $7(15,9)$ \\
Disorientation of place or time & $2(4,5)$ \\
Other (anxiety, lack of confidence, migraine) & $1(2,2)$ \\
\hline
\end{tabular}

Median length of ICU stay in PCS patients was 10 days, which was significantly different compared to patients without PCS with 5 days median length of stay $(\mathrm{p}<0,001)$. C-statistics showed that a length of stay cut- 
off of 7,5 days predicts the PCS incidence (AUC $=0,824 ; \mathrm{p}<0,001$ ). From the cutoff, patients with ICU stay of 8 days were compared with patients with ICU stay of $>8$ days for the incidence of PCS, and was significantly different with RR $(95 \% \mathrm{CI})=2,5(1,7-3,7) ; \mathrm{p}<0.001$. This result indicates that patients with the length of stay of $>8$ days had a 2,5 times greater risk of developing PCS in the future.

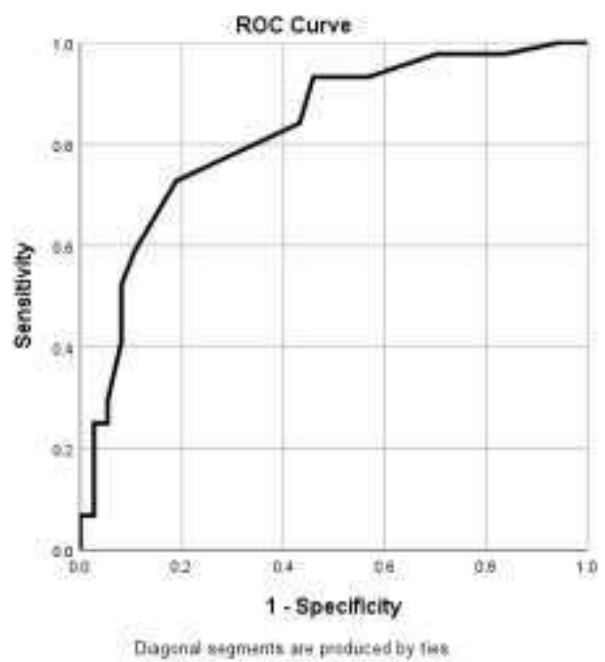

Fig.1. ROC curve of ICU length of stay with PCS incidence

3.3. Correlation of length of stay with mortality rate

We analyzed the correlation of mortality with the length of stay and included 104 subjects. As much as $21,2 \%$ of these subjects were died, with the median length of stay of 10 days in the non-survived group and 7 days in the survived group $(\mathrm{p}=0.042)$. ROC curve cutoff showed a result of 8,5 days ICU stay predicts the mortality with AUC $0,641, p=0,043$. Compared to those with 8 days or less of ICU stay, patients with $>8$ days stay had 2,4 times greater risk of mortality $(\mathrm{RR}=2,4, \mathrm{CI}(1,1-5,2), \mathrm{P}=0,042)$

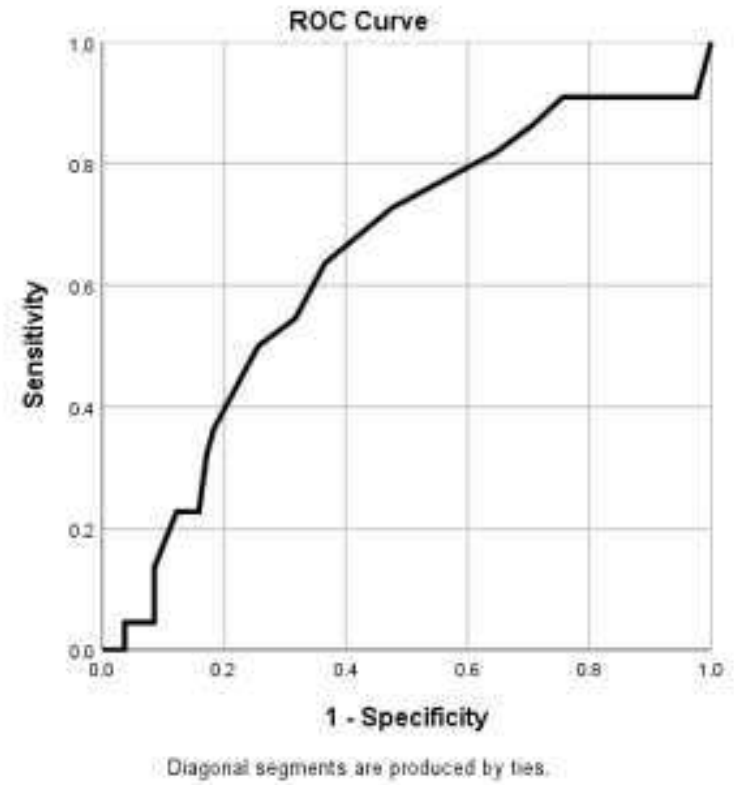

Fig.2. ROC curve of ICU length of stay as the predictor of mortality

3.4 Association of Ventilator usage duration towards PCS and mortality in survived COVID-19 patients after ICU discharge

Ventilator usage duration did not significantly correlated with the mortality and PCS incidence. In this study, 37 patients needed mechanical ventilation support during the ICU stay, with the average usage duration of 8 days in PCS patients and 3 days in non-PCS patients; and the average duration of 8 days in non-survived patients and 7 
days in survived patients ( $\mathrm{p}=0,993$ and $\mathrm{p}=0,193$, respectively). In 37 subjects who were mechanically ventilated, 15 patients $(40,5 \%)$ were died and 22 patients $(59,5 \%)$ were included for the sub-analysis of ventilator usage and PCS incidence.

\section{Discussion}

Our study showed that among the COVID-19 survivors, 22\% patients experienced PCS, with the most prevalent symptoms of fatigue in $79.5 \%$ of PCS patients, cough in $40.9 \%$ and insomnia in $29.5 \%$ as well as myalgia/arthralgia in $15.9 \%$ PCS patients. PCS was similar to the other post-infection syndromes following chikungunya outbreak and Ebola.(7) Chronic tissue damage and inflammation were based on the underlying factors. A study showed impairments in respiratory and cardiovascular as well as neurological systems, correlated to PCS.(8) Long inflammation of the lungs was reflected in the prolonged cough symptom. Some other studies stated that PCS incidence under intensive care was relatively higher compared to the ones taken care in low care unit $(46,9 \%$ vs. $23,5 \%)$. Alongside with our study, the most frequent symptoms developed were fatigue (72\%), followed by shortness of breath $(65,5 \%)$ and psychological distress $(46,9 \%) .(9)$ A Mediterranean cohort study, PCS incidence dominated for $50.9 \%$ of overall survived COVID-19 patients; of these patients, $60 \%$ was diagnosed with severe COVID-19 pneumonia when they were hospitalized. Fatigue and shortness of breath were the 2 most common symptoms of PCS in this study.(10) another cohort study showed an incidence of PCS in Belgium for up to 87,5\% patients complained their decreasing of health performance since diagnosed with COVID-19 and their physical performance were not able to be retrieved like before the SARS-COV-2 infection; of these patients, 90\% underwent PICS (post-intensive care syndrome). More than one third of patients with PCS had comorbidities of hypertension and diabetes mellitus.(11) these results were alongside with our study that patients with PCS had preexisting Diabetes mellitus and or hypertension.

Prior studies explained above has stated that the incidence of PCS was significantly found more frequent in patients who were taken care in ICU compared to the low-care wards. Our study also analyzes the correlation of ICU length of stay as the predictor of PCS incidence, and was proved that an ICU stay of more than 8 days was significantly correlated with the future PCS incidence of these patients $(p<0.001)$. PICS is the development of new symptoms or the increase of pre-existing symptoms targeting the physical domains like cognitive or mental after experiencing severe or critical illness in ICU, and could be from 5 to 15 years.(12) PICS patients tends to develop PCS after ICU discharge. Muscle weakness, myopathies, and neuropathies are the underlying physical deterioration that cause the PCS symptoms like fatigue. Muscle weakness was caused by the microvascular ischemia, catabolism, and long immobility while long bed-rest in ICU, this immobility skeletal muscle's cellular breakdown. Microvascular damage leads to the neural ischemia because lack of the vascularization in neural tissues, sodium channel dysfunction, and neural mitochondria impairment. $(13,14)$ In accordance with our study findings that the longer the ICU stay, the more risk of PCS after ICU discharge. Insomnia and mental impairment in COVID-19 patients also found in the group of patients without preexisting mental disorder. A study including 62.354 COVID-19 patients whom without underlying psychiatric diagnosis before, proved that psychiatric disorder could developed 14 until 90 days after COVID-19 diagnosis (HR 2,1 95\%CI 1,8-2,5), with anxiety as the most prevalent psychiatric diagnosis, followed by insomnia and dementia.(15) Similar to our findings, another study showed that after 10 days of ICU stay, patients tend to develop insomnia and cognitive disturbance 4 months after ICU discharge.(16) the reason behind the mental impairment that correlated with the ICU stay were the inability to communicate, environment factors (alarm of medical device, too bright lamps), midnight procedures maybe the hand strainer, intubation, lack of sleep during ICU stay.(17)

Length of stay in ICU not only predicting the PCS incidence in the future, but also mortality after ICU discharge (survived COVID-19 but passed away in subsequent periods of time). Long term mortality rate in COVID-19 survivor who were admitted to ICU was 21,2\%. In Germany, mortality of 90 days after ICU discharge was $27.9 \%$, with the predictors of coagulopathy, age, and obese type II that were correlated with 180 days mortality after ICU discharge.(18) in Australia, similar results demonstrated that ICU length of stay was correlated with long-term mortality but, comorbidities, age, Acute physiology score predict the long-term mortality better than the length of stay.(19) 
Physiological and reserve alteration are present in many chronic diseases, and long period of intensive care is related to the nosocomial infections, immunosuppression, malnutrition, suppression of pituitary hormones, myopathies, post-traumatic stress disorder, and brain dysfunction.(20)

Severe and critical COVID-19 manifestation often requires intensive care and sometimes ventilatory support is also needed for some patients with the respiratory distress progression. In our study, the duration of ventilator support usage was not significantly associated with the incidence of PCS and also not associated with mortality after ICU discharge with the follow-up time of 3 months. On the contrary, some studies showed that mechanical ventilation was one the risk factors of developing PICS. Ventilator support usage of more than 7 days was correlated with muscle weakness, and the long period of bed-rest was also required in mechanically ventilated patients. $(13,21)$ Long-term mortality risk after survived from COVID-19 was related to the elder age, functional status before admission.(22) A systematic review of patients with prolonged ventilator usage, one year mortality was $60 \%$, with the interacted variables of age. Age was related with cardiovascular compromise, hematological impairment, and renal dysfunction, which were also correlated to the failure of ventilator support weaning.(23)

These inconsistent results may be because of the different time of long-term follow up. Our study follow-up was 3 months after ICU discharge, while the other studies analyze the mortality after a year of discharge. Our study have some limitations that could be improved with further studies relating to the PCS and mortality in survived COVID-19 patients. Functional capacity questionnaire, multivariable analysis, and face-to-face interview will improve this study. A bigger sample size and multicenter study are also recommended for elaboration.

5. Conclusion

We conclude that PCS incidence after ICU discharge was $53,7 \%$, with the most frequent presenting symptoms of fatigue, followed by persistent cough, and insomnia. Length of stay in ICU significantly predict the incidence of PCS and long-term mortality (3 month) of survived COVID-19 patients after ICU discharge, but ventilator support usage was not a predictor of the upcoming PCS incidence and 3-months-mortality after ICU discharge in COVID-19 survivors.

\section{References}

1. World Health Organization. International Guidelines for Certification and Classification (Coding) of Covid-19 as Cause of Death. Who [Internet]. 2020;(April):14. Available from: https://www.who.int/classifications/icd/Guidelines_Cause_of_Death_COVID-19.pdf

2. Susilo A, Rumende CM, Pitoyo CW, Santoso WD, Yulianti M, Herikurniawan H, et al. Coronavirus Disease 2019: Tinjauan Literatur Terkini. J Penyakit Dalam Indones [Internet]. 2020 Apr 1 [cited 2021 Nov 17];7(1):45-67. Available from: http://www.jurnalpenyakitdalam.ui.ac.id/index.php/jpdi/article/view/415

3. Carfì A, Bernabei R, Landi F. Persistent Symptoms in Patients After Acute COVID-19. JAMA [Internet]. 2020 Aug 11 [cited 2022 Jan 5];324(6):603-5. Available from: https://pubmed.ncbi.nlm.nih.gov/32644129/

4. de Melo GD, Lazarini F, Levallois S, Hautefort C, Michel V, Larrous F, et al. COVID-19-related anosmia is associated with viral persistence and inflammation in human olfactory epithelium and brain infection in hamsters. Sci Transl Med [Internet]. 2021/05/03. 2021 Jun 2;13(596):eabf8396. Available from: https://pubmed.ncbi.nlm.nih.gov/33941622

5. NATIONAL INSTITUTE FOR HEALTH AND CARE EXCELLENCE COVID-19 rapid guideline: managing the long-term effects of COVID-19 (NG188). 2020;19(December):1-17.

6. PDPI, PERKI, PAPDI, PERDATIN, IDAI. Pedoman tatalaksana COVID-19. Burhan E, Susanto AD, Isbaniah F, Nasution SA, Ginanjar E, Pitoyo C wicaksono, et al., editors. Pedoman Tatalaksana COVID19 [Internet]. 2020 [cited 2021 Nov 10];1-138. Available from: https://www.papdi.or.id/download/983pedoman-tatalaksana-covid-19-edisi-3-desember-2020

7. Brodin P. Immune determinants of COVID-19 disease presentation and severity. Nat Med [Internet]. 2021;27(1):28-33. Available from: https://doi.org/10.1038/s41591-020-01202-8

8. Yong SJ. Long-Haul COVID-19: Putative Pathophysiology, Risk Factors, and Treatments. 2020 Dec 10 [cited 2022 Jan 7]; Available from: https://www.preprints.org/manuscript/202012.0242/v1

9. Halpin SJ, McIvor C, Whyatt G, Adams A, Harvey O, McLean L, et al. Postdischarge symptoms and rehabilitation needs in survivors of COVID-19 infection: A cross-sectional evaluation. J Med Virol $\begin{array}{lllllll}\text { [Internet]. } 2021 & \text { Feb } 1 & \text { [cited } 2022 \text { Jan 7];93(2):1013-22. Available from: } \\ \text { www.ijr.org }\end{array}$ 
https://onlinelibrary.wiley.com/doi/full/10.1002/jmv.26368

10. Moreno-Pérez O, Merino E, Leon-Ramirez JM, Andres M, Ramos JM, Arenas-Jiménez J, et al. Post-acute COVID-19 syndrome. Incidence and risk factors: A Mediterranean cohort study. J Infect [Internet]. 2021 Mar 1 [cited 2022 Jan 7];82(3):378-83. Available from: http://www.journalofinfection.com/article/S0163445321000098/fulltext

11. Pavli A, Theodoridou M, Maltezou HC. Post-COVID Syndrome: Incidence, Clinical Spectrum, and Challenges for Primary Healthcare Professionals. Arch Med Res. 2021 Aug 1;52(6):575-81.

12. Biehl M, Sese D. Post-intensive care syndrome and COVID-19 - Implications post pandemic. Cleve Clin J Med [Internet]. 2020 Aug 5 [cited 2022 Jan 7]; Available from: https://www.ccjm.org/content/early/2020/07/29/ccjm.87a.ccc055

13. Inoue S, Hatakeyama J, Kondo Y, Hifumi T, Sakuramoto H, Kawasaki T, et al. Post-intensive care syndrome: its pathophysiology, prevention, and future directions. Acute Med Surg [Internet]. 2019 Jul 1 [cited 2022 Jan 7];6(3):233-46. Available from: https://onlinelibrary.wiley.com/doi/full/10.1002/ams2.415

14. Rawal G, Yadav S, Kumar R. Post-intensive care syndrome: An overview. J Transl Intern Med. 2017 Jun 30;5(2):90-2.

15. Taquet M, Luciano S, Geddes JR, Harrison PJ. Bidirectional associations between COVID-19 and psychiatric disorder: retrospective cohort studies of 62354 COVID-19 cases in the USA. The lancet Psychiatry [Internet]. 2021 Feb 1 [cited 2022 Jan 7];8(2):130-40. Available from: https://pubmed.ncbi.nlm.nih.gov/33181098/

16. Group TWC for the CS. Four-Month Clinical Status of a Cohort of Patients After Hospitalization for COVID-19. JAMA [Internet]. 2021 Apr 20;325(15):1525-34. Available from: https://doi.org/10.1001/jama.2021.3331

17. Dziadzko V, Dziadzko MA, Johnson MM, Gajic O, Karnatovskaia L V. Acute psychological trauma in the critically ill: Patient and family perspectives. Gen Hosp Psychiatry. 2017 Jul 1;47:68-74.

18. Günster C, Busse R, Spoden M, Rombey T, Schillinger G, Hoffmann W, et al. 6-month mortality and readmissions of hospitalized COVID-19 patients: A nationwide cohort study of 8,679 patients in Germany. PLoS One [Internet]. 2021 Aug 1 [cited 2022 Jan 7];16(8):e0255427. Available from: https://journals.plos.org/plosone/article?id=10.1371/journal.pone.0255427

19. Williams TA, Ho KM, Dobb GJ, Finn JC, Knuiman M, Webb SAR. Effect of length of stay in intensive care unit on hospital and long-term mortality of critically ill adult patients. Br J Anaesth [Internet]. 2010 Apr 1 [cited 2022 Jan 7];104(4):459-64. Available from: http://www.bjanaesthesia.org/article/S0007091217336504/fulltext

20. Moitra VK, Guerra C, Linde-Zwirble WT, Wunsch H. Relationship between ICU Length of Stay and Long-Term Mortality for Elderly ICU Survivors. Crit Care Med [Internet]. 2016 Apr 1 [cited 2022 Jan 7];44(4):655-62. Available from: https://journals.lww.com/ccmjournal/Fulltext/2016/04000/Relationship_Between_ICU_Length_of_Stay _and.2.aspx

21. Ahmad MH, Teo SP. Post-intensive Care Syndrome. Ann Geriatr Med Res [Internet]. 2021 [cited 2022 Jan 7];25(2):72-8. Available from: http://www.e-agmr.org/journal/view.php?doi=10.4235/agmr.21.0048

22. Chelluri L, Im KA, Belle SH, Schulz R, Rotondi AJ, Donahoe MP, et al. Long-term mortality and quality of life after prolonged mechanical ventilation. Crit Care Med [Internet]. 2004 [cited 2022 Jan 7];32(1):619. Available from: https://journals.lww.com/ccmjournal/Fulltext/2004/01000/Long_term_mortality_and_quality_of_life_af ter.7.aspx

23. Dettmer MR, Damuth E, Zarbiv S, Mitchell JA, Bartock JL, Trzeciak S. Prognostic Factors for LongTerm Mortality in Critically Ill Patients Treated With Prolonged Mechanical Ventilation: A Systematic Review. Crit Care Med [Internet]. 2017 Jan 1 [cited 2022 Jan 7];45(1):69-74. Available from: https://pubmed.ncbi.nlm.nih.gov/27618272/ 